\title{
ANALYSIS OF COLOR AND SPECTRAL CHARACTERISTICS OF HEN EGG YOLKS FROM DIFFERENT MANUFACTURERS
}

\author{
Mariya Georgieva-Nikolova ${ }^{1}$, Atanas Genchev ${ }^{2}$, Zlatin Zlatev ${ }^{1}$ \\ ${ }^{1}$ Faculty of Technics and Technologies, Trakia University, Bulgaria \\ 38 Graf Ignatiev str., 8602, Yambol, Bulgaria \\ e-mail: zlatin.zlatev@trakia-uni.bg \\ ${ }^{2}$ Sub-Department of Poultry Farming, Department of Animal Husbandry - \\ Non-Ruminants and Other Animals, Agrarian Faculty, \\ Trakia University, Bulgaria \\ Studentski Grad, 6000, Stara Zagora, Bulgaria
}

\begin{abstract}
In the present work an analysis of the separability of hen egg yolks from different manufacturers is made using image and spectral processing and analysis techniques. Apparent properties of three types of egg yolks were determined and a comparative analysis of these properties was made. Discriminant and SVM (Support vector machines) classifiers were used for classification. A general classification error with lower values is obtained with the $b$ (Lab) color component. In the studies of the spectral characteristics of egg yolks from different manufacturers, the highest accuracy of separation of the target areas is obtained with the kernel SVM classifier combined with the kernel variant of the principal components. When using this classifier, general classification errors of up to $1 \%$ were obtained. The results confirm the hitherto known research in this area because the major part of the chicken egg yolk properties studied are visible properties that can be analyzed in the visible spectrum of the reflected light.
\end{abstract}

Keywords: color components, spectral characteristics, egg yolks, classifiers.

\section{INTRODUCTION}

In recent years, due to the increasing competition in the egg market, attention has been paid to certain qualitative indicators to increasingly satisfy end-user preferences. In particular, commercially available eggs are eaten with a certain color of yolk. According to surveys made in European Union countries (France, Germany, Italy, Great Britain, Spain, Poland and Greece), consumers have marked the color of yolk as one of the main parameters for assessing egg quality $[4,8,13]$.

The results of the research are varied and give specific guidelines and recommendations to bird poultry feeders to achieve the desired egg yolk color and maintain it for a long time to meet the ultimate goal of meeting the requirements of end users.

In order to accomplish this task, preliminary analyzes of the separability of eggs by the different producers are required by color characteristics and spectral characteristics. The absence of such an analysis would lead to an increase in measurement errors in the application of these methods for rapid and non-destructive assessment of the quality of eggs. Taking this into account, the main objective of this article is to evaluate the possibility of using color and spectral characteristics of egg yolks to distinguish hen eggs using statistical methods by analyzing existing relationships between statistical assessments of different color and spectral characteristics of eggs from different manufacturers. 


\section{IRTIL $\\rangle$}

Ipplied Resseirlores in Technics, Technologies and Educration

Journal of the Faculty of Technics and Technologies, Trakia University https://sites.google.com/a/trakia-uni.bg/artte/

\section{RELATED WORKS}

When samples of egg yolks corresponding to 8,10, 12 and 14 of the DSMYFF Vessel Venture (DSMYCF) 8, 10, most of the surveyed users in European studies express a preference for the darkest colors. They also believe it is important that all eggs in one package have the same or similar yolk color, given that the homogeneity of the eggs is an indicator of consistently good quality $[20,21,22]$. DSM Yolk Color Vetch (DSMYCF) is widely used by egg producers as a standard for measuring yolk color as a routine and reliable tool. Each part of the fan has a color that is objectively measured and can be reproduced. By using the fan to determine the desired yolk color and the corresponding feeding of the hens, the color of yolk can not only be achieved but can also be reproduced again [6]. As with all other birds and laying hens, the color of yolk is predominantly determined by the content and profile of pigmentation carotenoids present in the diet. Thus, once the yolk color or DSMYCF is determined, it is a relatively easy process to control by specifying / formulating the food and the carotenoid content of the feed required to achieve this goal [27,30].

Carotenoids can be included in nutrition using certain raw materials, such as corn or grass meal, or the inclusion of specific feed additives. Thus, the nutritionist can determine, on the basis of the local costs and availability of the raw material and the desired yolk color, a costeffective approach to producing the eggs of the color needed to meet the quality criteria demanded by consumers. There are three major yellow carotenoids (lutein, zeaxanthin and apoester) and three major red carotenoids (canthaxanthin, citranxanthin and capsantin / capsorubin) used for egg yolk pigmentation, each of which has unique properties (eg color shades and deposition efficiency - proportion of food intake that is absorbed and deposited in egg yolk), which determines the effectiveness of its pigmentation [13]. The primary criterion for yellow carotenoids is to provide a strong yellow base that is important for developing a good end color. The most important characteristic of the yellow carotenoids during the saturation phase is their deposition efficiency, which is approximately three times greater than that of lutein or zeaxanthin (about 10-20\%). Thus, three times more lutein / zeaxanthin than apoester is added to the feed to ensure the same degree of yellow pigmentation in the egg yolk [10].

Red carotenoids are the main reason for the development of a golden yellow color in yolk, both the depositional efficacy and the color properties of individual carotenoids are important. The effectiveness of canthaxanthin deposition is significantly higher than that of citranxanthin or capsantin/ capsorubin. Different studies investigate the effect on egg yolks of the following plant foods: dried grain distilleries [28]; marigold [15]; alfalfa, marigold and tomato [16]; sweet green pepper [28]. It seeks a certain effect on the color of yolk when adding to the normal diet a certain percentage of crops and other additives. Research varies from country to country by seeking lower costs, using certain plant species and other additives.

Effects on the yolk color of various dietary supplements such as lutein, spray-dried chlorella and synthetic carotenoids are also studied [12]; heterotrophic chlorella [19]; low DDGS dried beans [10]; vegetable oils rich in polyunsaturated fatty acids [13]. Studies related to changes in quality and yolk color are also directed to: irradiation [24]; rheological measurements [20]; enrichment with omega-3 and carotene [3]; the influence of egg shell color on the level of antibodies in egg yolk [5].

In addition to DSM Yolk Color method (DSMYCF), which is recommended for handling, comparing and presenting information related to egg yolk color, other used technical means are: colorimetric, chromometer, spectrophotometer, micrometre, chromatograph. Information is usually processed by: texture profiling and sensory analysis, chemical analysis, liquid and gas chromatography, differential scanning colorimetry. 


\section{ARITIE $Y$}

Ipplied Resseirlohes in Technics, Technologies and Eductition

Journal of the Faculty of Technics and Technologies, Trakia University https://sites.google.com/a/trakia-uni.bg/artte/

The method for determining the protein content of eggs in a spectrophotometric manner $[1,3]$ is suitable for egg yolks and for proteins. Remove egg yolk or egg whites and stir until homogeneous. Figure 1 shows a graph for determining the protein content of eggs in their absorption at three wavelengths of 540, 595 and 750nm.

\section{Eggs Protein content}

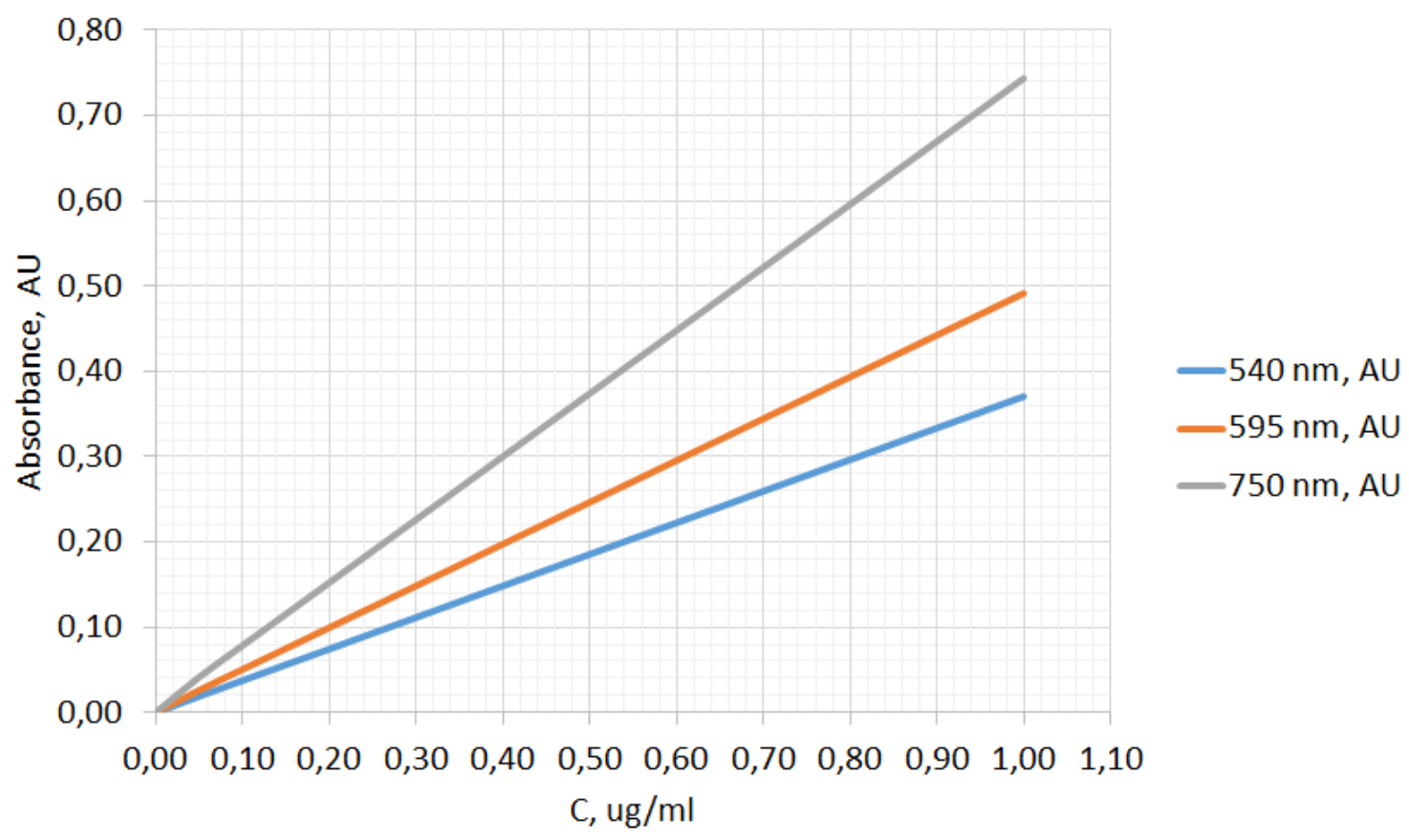

Figure 1. Graphical Determination of Protein Content in Eggs

The three wavelength absorption transformation models are:

$$
C_{540}=\frac{A_{540}-0,0008}{0,3687} ; \quad C_{595}=\frac{A_{595}-0,0018}{0,4888} ; \quad C_{750}=\frac{A_{750}-0,0047}{0,7381}
$$

where with $A_{x x x}$ is the absorption at a given wavelength.

A method for determining carotenoid content in eggs is known. With this method, the egg yolks are separated and mixed until homogeneous. Take $1 \mathrm{~cm}^{3}$ of the liquid, transfer to a 50 $\mathrm{cm}^{3}$ volumetric flask and make up to the mark with ethyl alcohol. The resulting solution was stirred and filtered. The filtrate is used to determine the optical density (absorption) of a spectrophotometer at a wavelength of $450 \mathrm{~nm}$. As a control sample to reset the spectrophotometer, ethyl alcohol is used.

The content of carotenoids is calculated by the formula:

$$
C_{450}=\text { D. 0,00208. } a \cdot 100, \frac{\mathrm{mg}}{\mathrm{cm}^{3}}
$$

where $D$ is the optical density of the solution; 0.00208 - the amount of carotene in $\mathrm{mg}$ corresponding to the coloring of the standard sample; $\mathrm{a}$ - dilution of the solution, $\mathrm{cm}^{3}(\mathrm{a}=$ $50)$. 


\section{ARTTIE}

Ipplied Researleches in Technics, Technologies and Eductation

Journal of the Faculty of Technics and Technologies, Trakia University https:///ites.google.com/a/trakia-uni.bg/artte/

From the review of literary sources, it has been found that there is a need to carry out a more in-depth analysis of the known methods and approaches that have been applied so as to improve and facilitate the classification process for introduction into automated systems.

\section{MATERIAL AND METHODS}

Eggs from laying hens from three Bulgarian manufacturers were analyzed. Eggs are purchased commercially. Measurements of 30 eggs from each manufacturer were made, totaling 90 eggs.

Color digital images with a Prestigio MultiPad Wize 3407 (PRESTIGIO.COM) tablet video camera are captured, with a resolution of $640 \times 480$ pixels and a 24-bit color depth.

Colorimetric measurements were made using a Lenovo A2010 (Lenovo Group Ltd.) mobile phone and an Android application, ColorMeter Free - color picker (VisTech.Projects Inc.). The egg is placed on a background that is in contrast to the yolk color.

Examples of color digital images of the three manufacturers egg yolks of the present work, conventionally designated as P1, P2 and P3, are shown in Figure 2.

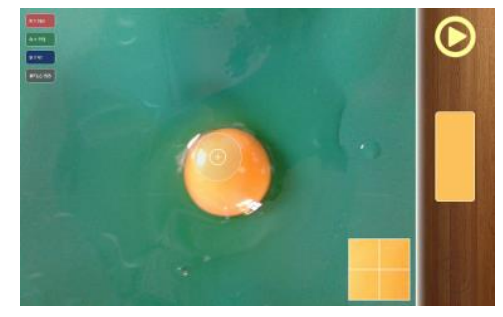

a) P1

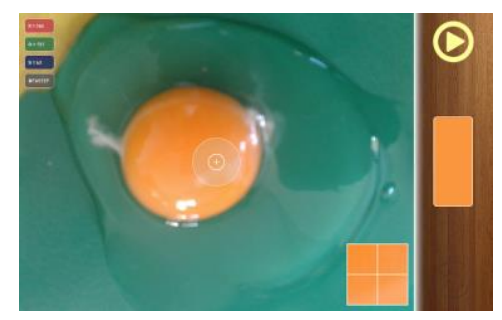

b) P2

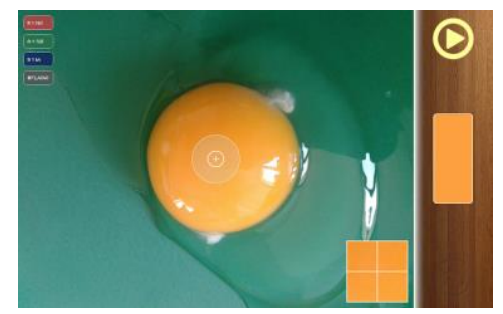

c) P3

Figure 2. Egg yolks from different manufacturers

Three color models are used RGB, Lab, LCH [17,18,25].

Distance functions between color components are used: Mahalanobis, Euclidean distance, Cityblock distance, Chebychev distance and Fisher discriminant ratio:

Mahalanobis (Mah)

$d_{s t}^{2}=\left(x_{s}-y_{t}\right) C^{-1}\left(x_{s}-y_{t}\right)^{\prime}$

Euclidean (Euc)

$$
d_{s t}^{2}=\left(x_{s}-y_{t}\right)\left(x_{s}-y_{t}\right)^{\prime}
$$

Cityblock (Cb)

$$
d_{s t}=\sum_{j=1}^{n}\left|x_{s j}-y_{t j}\right|
$$

Chebychev (Cheb)

$$
d_{s t}=\max _{j}\left\{\left|x_{s j}-y_{t j}\right|\right\}
$$

Fisher discriminant ratio (FDR)

$$
d_{s t}=\frac{(\bar{x}-\bar{y})^{2}}{S D_{x}^{2}+S D_{y}^{2}}
$$




\section{ARTTIE $Y$}

Ipplied Resseirlores in Technics, Technologies and Educration

Journal of the Faculty of Technics and Technologies, Trakia University https://sites.google.com/a/trakia-uni.bg/artte/

where $C$ is a covariance matrix; $x$ and $y$ are the compared vectors; max - maximum; SD standard deviation.

The obtaining of spectral characteristics of egg yolks was done by converting LMS model values into reflectance spectra in the VIS range, in the range $390-730 \mathrm{~nm}$, by mathematical dependencies where conversion is possible in both directions of equality [14].

Mathematical dependencies for conversion from RGB to spectra in the visible spectral range $\left(\mathrm{S}_{\mathrm{VIS}}\right)$ are:

$$
\begin{gathered}
X Y Z=R G B \cdot M_{X Y Z} \\
M_{X Y Z}=\left[\begin{array}{lll}
0,5767 & 0,2974 & 0,027 \\
0,1855 & 0,6273 & 0,0707 \\
0,1882 & 0,0753 & 0,9911
\end{array}\right] \\
L M S=X Y Z \cdot M_{L M S} \\
M_{L M S}=\left[\begin{array}{ccc}
0,7328 & 0,4296 & -0.1624 \\
-0.7036 & 1.6975 & 0.0061 \\
0.0030 & 0.0136 & 0.9834
\end{array}\right] \\
L=\int_{380}^{780} A(\lambda) \bar{L}(\lambda) d \lambda ; M=\int_{380}^{780} A(\lambda) \bar{M}(\lambda) d \lambda ; S=\int_{380}^{780} A(\lambda) \bar{S}(\lambda) d \lambda \\
S_{V I S}=\sqrt{\Delta L^{2}+\Delta M^{2}+\Delta S^{2}}
\end{gathered}
$$

where $M$ is a matrix for transformation under the specified observer and illumination conditions. XYZ conversion functions are used to the LMS color model [9]. $A(\lambda)$ is a matrix for color transformation to reflectance spectra in the VIS range, according to observer used and illumination. These matrices are available in [23] for the VIS range.

The transmission T\% is the percentage of emitted light that passed through the sample and has fallen on the detector. $T \%=\log (1 / R)$, where $R$ is the reflection.

Absorption of light Abs, AU (optical density) is the light dimming in passage and through substance due to absorption and consumption of part of the light energy $A=2-\log (T \%)$. Reverse conversion to transmission is $T \%=100 \cdot\left(10^{\wedge}-A\right)$.

The conversion functions applied are $10^{\circ}$ observer (Stiles and Burch $10^{\circ}$, RGB (1959)) and illumination D65 (average daylight with UV component (6500K)).

The methods used for spectral characteristics data reduction are: area under curve, major components, latent variables and kernel variant of major components.

An "area under curve" (AUC) coefficient [34] was used to describe the spectral characteristics of the object areas. AUC criterion is used to identify processes to compare them. It is defined in the interval [a,b] as:

$$
A U C=\int_{a}^{b} f(x) d x
$$

Latent variables (LV) obtained by partial least squares regression (PLS) [25]. PLS (Partial least-squares) regression is a technique used for data that contains correlated predictive variables. This technique constructs new predictive variables known as components as a linear combination of the original predictive values. PLS constructs these components by assuming the observed values, resulting in a more accurate model with better forecasting. In the principal components analysis (PCA) [25,26,31], the extraction of characteristic

IRTIIE Vol. 7, No. 2, 2019 ISSN 1314-8788 (print), ISSN 1314-8796 (online), doi: 10.15547/artte.2019.02.005 


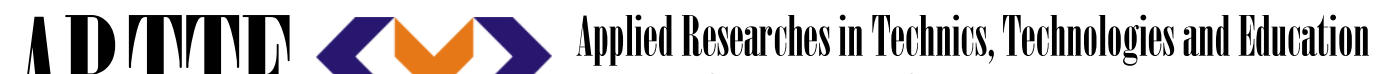 Journal of the Faculty of Technics and Technologies, Trakia University https://sites.google.com/a/trakia-uni.bg/artte/}

properties is a transformation of the original data with all of its variables into a sample of reduced ones. All measurements or variables that are designed in a small size area are used. The reasons for the extraction of characteristic properties are as follows:

- Decrease the bandwidth of input data;

- Provide fewer features of accelerating classification;

- To obtain a smaller amount of data (ideally two dimensions) with minimal loss of information, and thus the data is better visualized.

The principal component analysis (PCA) creates an orthogonal coordinate system where the axes are arranged according to the dispersion in the original data to which the corresponding major component and the dispersions and the principal values are related. In the covariate data matrix:

$$
K=E\left[(x-\bar{x})^{T}(x-\bar{x})\right]
$$

The covariance matrix sums the dispersions in the data, its own vectors show the main directions of the dispersion, and the associated eigenvalues give the amplitude of the dispersion around these axes. The proprietary vectors of the covariate matrix $\mathrm{K}$ bind as the main axis or principal components of the data dispersion. The analysis of the principal components uses an analysis of K's eigenvectors to find a reduced amount of space.

One of the widely used pattern-based learning methods (manifolds) is the kernel variant of PCA (kPCA). It is an expansion of the PCA using kernel techniques. Using a single kernel, the original kPCA transformation takes place in a new space of high dimension (reproduction kernel Hilbert space) with non-linear mapping of the input data.

The PCA starts with the calculation of the matrix $C$ of the matrix $X$ of the input data $m \times n$ :

$$
C=\frac{1}{m} \sum_{i=1}^{m} x_{i} x_{i}^{T}
$$

The data is then projected onto the first $k$ own vectors of the matrix. kPCA begins with the calculation of the data matrix $\mathrm{C}$ matrix once they have been transformed into a highdimensional space $\Phi(\mathrm{x})$ :

$$
C=\frac{1}{m} \sum_{i=1}^{m} \Phi\left(x_{i}\right) \Phi\left(x_{i}\right)^{T}
$$

Thereafter, the transformed data is projected on the first matrix $\mathrm{k}$ eigenvectors, similar to the PCA. The Kernel trick method is used to decompose part of the calculations so that the whole process can be realized without actually calculating $\Phi(\mathrm{x})$. $\Phi$ should be chosen as a known kernel.

Naive Bayes classifier [2,32]. One of the classical algorithms in machine learning is the Naive Bayse Classifier, which is based on the Bayes theorem for determining the apisterior probability of an event occurring. Assuming the "naive" assumption of conditional independence between each pair of features, the Naive Bayes' Theorem:

$$
P(y=c \mid x)=\frac{P(x \mid y=c) P(y=c)}{P(x)}
$$

where $P(y=c \mid x)$ is the probability that the object belongs to class $c$ (aposthorial probability of the class); $P(x \mid y=c)$ - the probability that the object $x$ encounters in the middle of the object

IRTIIE Vol. 7, No. 2, 2019 ISSN 1314-8788 (print), ISSN 1314-8796 (online), doi: 10.15547/artte.2019.02.005 


\section{ARTTIE $Y$}

Ipplied Resseirlores in Technics, Technologies and Educration

Journal of the Faculty of Technics and Technologies, Trakia University https://sites.google.com/a/trakia-uni.bg/artte/

of the class with; $P(y=c)$ - unconditional probability of encountering object $y$ in class with (a priori class probability); $\mathrm{P}(\mathrm{x})$ - unconditional probability of the object $\mathrm{x}$.

The purpose of the classification is to determine the class to which the object $x$ belongs. Therefore, it is necessary to find a probabilistic class of object $x$, ie. it is necessary for all classes to choose the one that gives the maximum probability $P(y=c \mid x)$.

$$
c_{\text {opt }}=\underset{c \in C}{\operatorname{argmax}} P(x \mid y=c) P(y=c)
$$

The discriminant function analysis used is a multidimensional data analysis that is applied when there is a need to "predict" the values of a clustering variable. This is also called classification or image recognition. Linear discriminant analysis constructs linear discriminative functions from predictors. The goal is to obtain a rule for assigning a new observation to a class. Assigning or "allocating" to a certain class of characteristics is also necessary for the present development. The following separation functions are used in the discriminative analysis:

- Quadratic - a quadratic discriminant function (second degree), distributes multivariate normal density data by calculation of covariance and collects them in a group;

- Diagquadratic - similar to the quadratic separating function, but uses the calculation of a covariance matrix diagonal (diagonal non-linear separating function);

- Mahalanobis - divides the data into groups by distance from Mahalonobis defining covariance in the data.

The other classifier used is the support vector machines (SVM) method [11,33], which is a model with teacher training and related algorithms for data analysis used for classification. In a learner, each element is associated with one of two categories, and the trainer algorithm builds a model in which the data is transformed into a new space. The created model represents the data in the new space so that there is separation between them.

The SVM analysis method uses the following separation functions:

- Quadratic - a quadratic separating function (second degree), distributes multivariate normal density data by calculation of covariance and collects them in a group;

- Polinomial - polynomial separating function;

- RBF - a separation function defined by radial basis elements.

The evaluation of the performance of the classifiers used is based on a general classification error, which is described by the formula:

$$
\mathrm{e}=\frac{\sum_{i=1}^{n}\left(\sum_{k=1}^{n} y_{i k}-y_{i i}\right)}{\sum_{i=1}^{n} \sum_{k=1}^{n} y_{i k}} .100, \%
$$

where $y_{i k}$ is the number of class i samples classified by classifier in class $k$; yii - number of correctly recognized samples; $\mathrm{k}=1 \ldots \mathrm{n}$ - number incorrectly assigned to a class i relative to the total number of samples; $n$ - number of classes.

Verification of normal data distribution was performed according to [7]. All calculations are made at a level of significance $\alpha=0,05$.

\section{RESULTS AND DISCUSSION}

An analysis of the color and spectral characteristics of egg yolks from different manufacturers was made. Color components are used. Spectral data is reduced by area under curve, latent variables and principal components. A naive Bayes, discriminant and SVM classifiers were used to analyze the reduced spectral data, depending on the egg manufacturer.

IRTIIE Vol. 7, No. 2, 2019 ISSN 1314-8788 (print), ISSN 1314-8796 (online), doi: 10.15547/artte.2019.02.005 


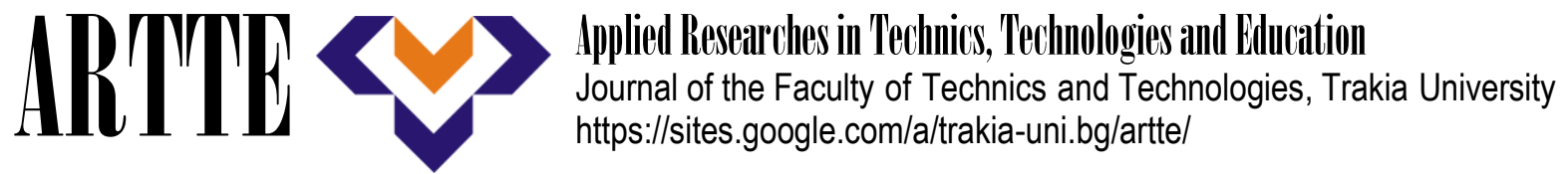

Figure 3 show the color components of the RGB, Lab and LCH color models of egg yolks from three manufacturers obtained with a video camera. An overlap of color component data is observed. Lab and LCH color models can be distinguished by manufacturer data 1 .

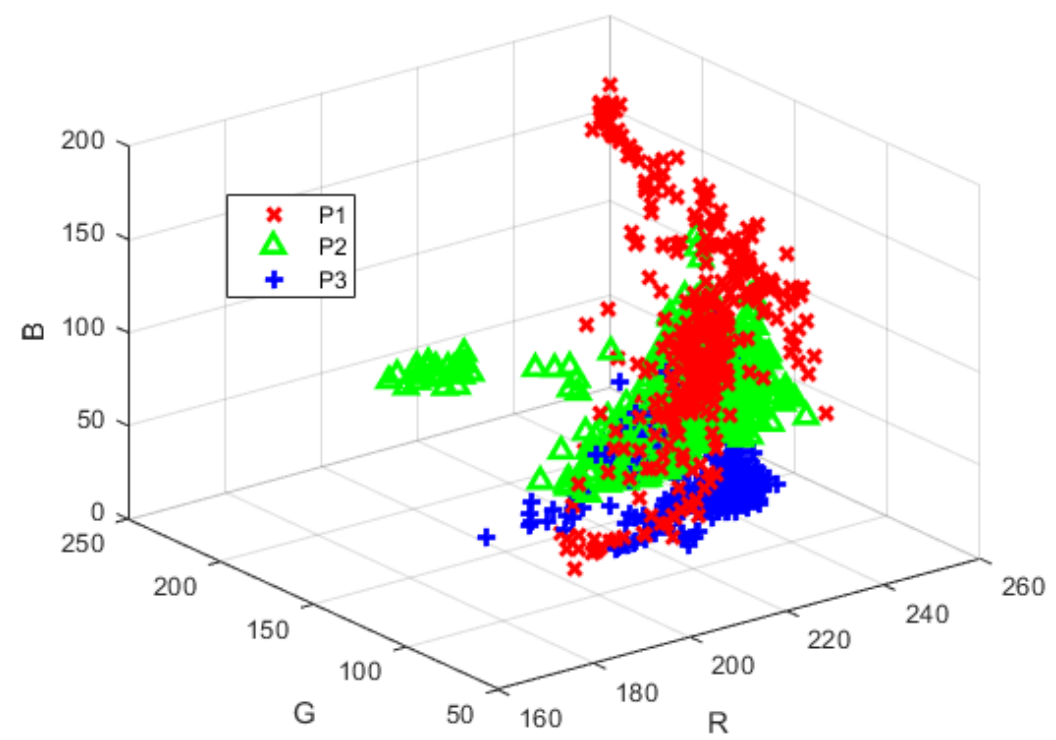

Figure 3a.

Color components obtained with a video camera. RGB model

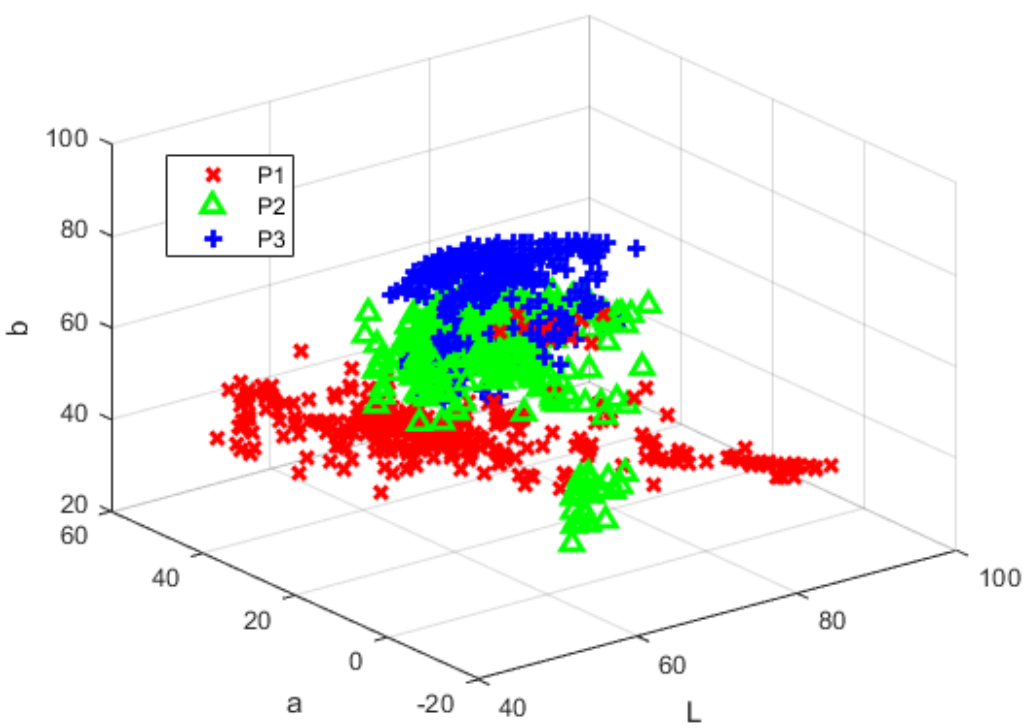

Figure 3b.

Color components obtained with a video camera. Lab model 


\section{IRTIII $Y$ Y}

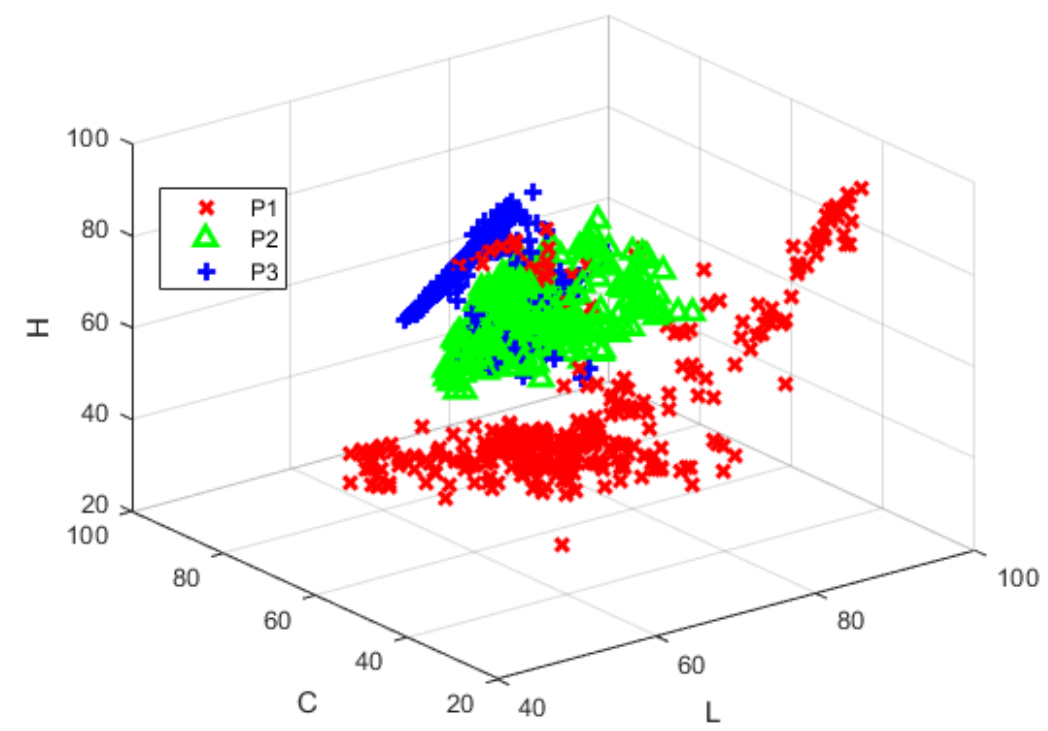

Figure 3c.

Color components obtained with a video camera. LCH model

Similar results are obtained with the colorimeter measurements. Figure 4 shows the color components of RGB, Lab, and LCH color models of egg yolks from three manufacturers. As with video camera data, the Lab and LCH color models show a separability for manufacturer's egg yolks 1 and a strong overlap for manufacturers 2 and 3 .

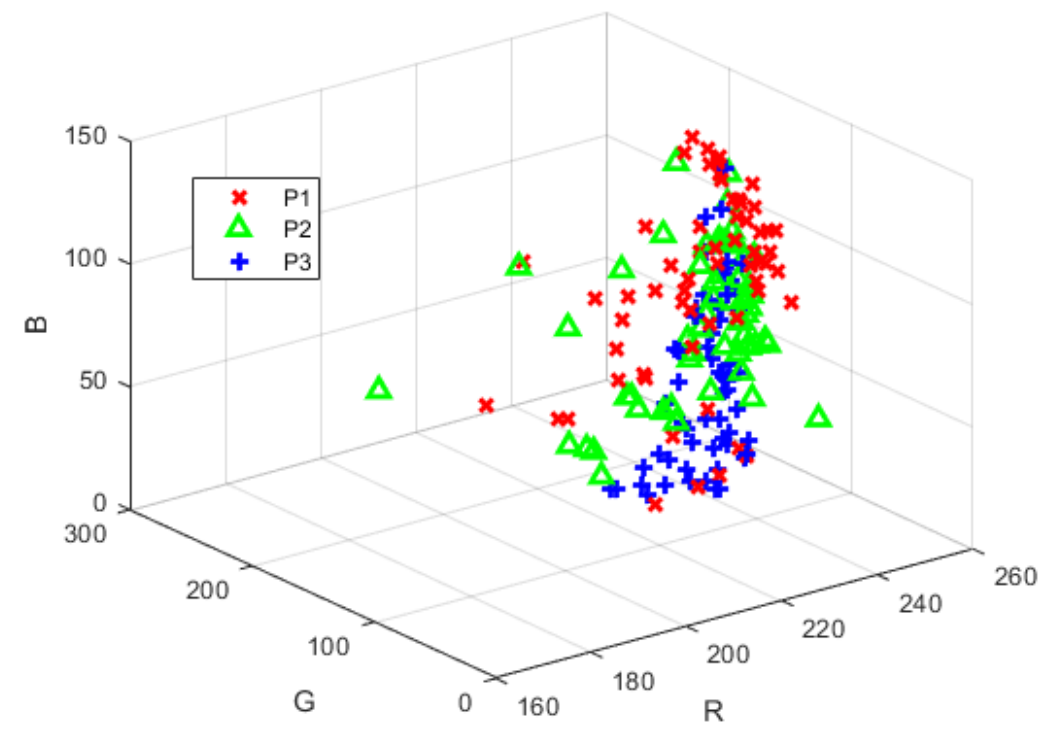

Figure 4a.

Color components obtained with a colorimeter. RGB model 


\section{IRTITE Ipplied Researreches in Technics, Technologies and Eductation Journal of the Faculty of Technics and Technologies, Trakia University https://sites.google.com/a/trakia-uni.bg/artte/}

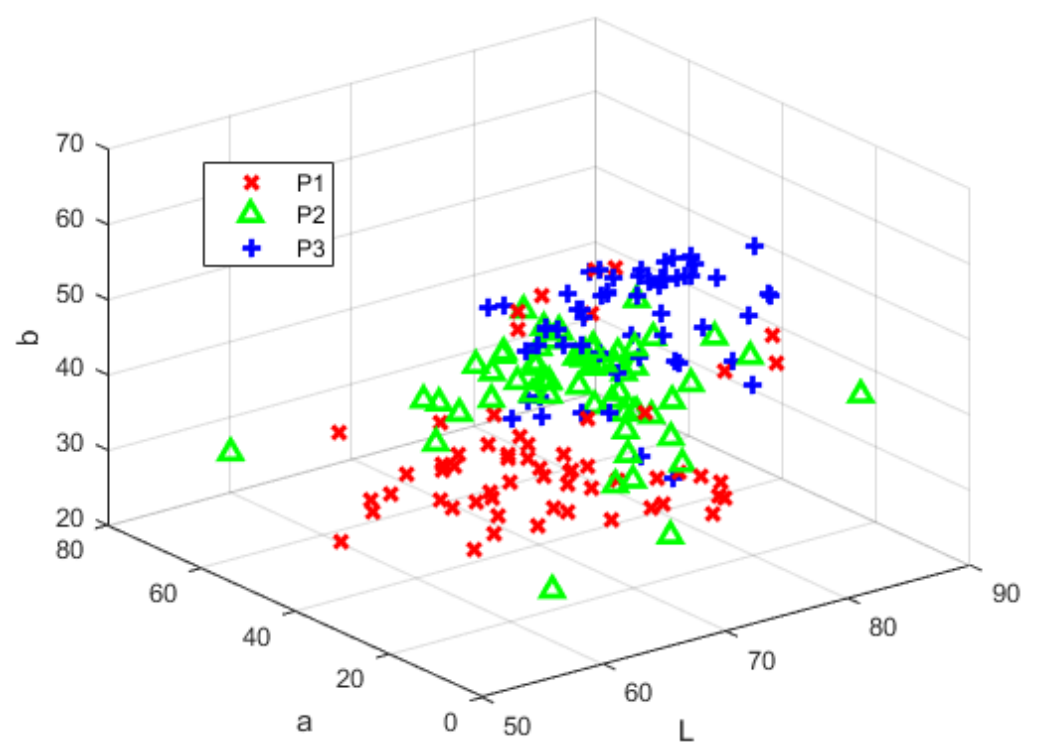

Figure 4b. Color components obtained with a colorimeter. Lab model

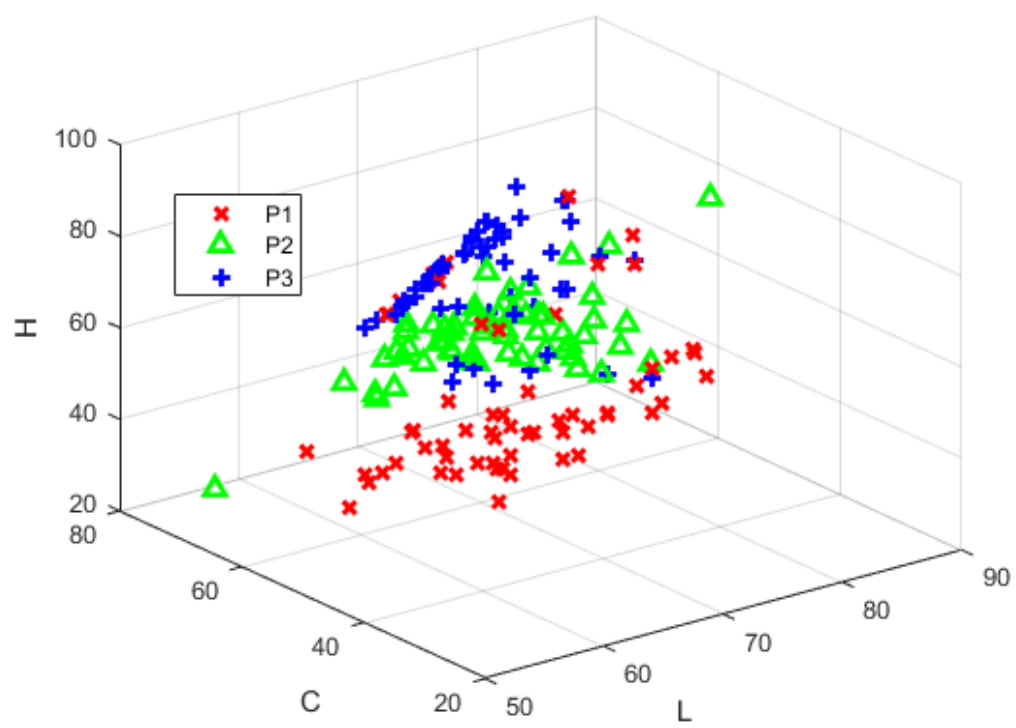

Figure 4c. Color components obtained with a colorimeter. LCH model

Table 1 gives a mean and standard deviation (SD) of color components of egg yolks of different manufacturers (P1, P2 and P3). The table shows that the color components measured with the video camera and the colorimeter are close. Large coefficients of variation ( $\mathrm{CV}=\mathrm{SD} /$ mean), with over $30 \%$, are mainly obtained with the RGB color model. This color model is not recommended for analysis because it is hardware dependent [18]. Lab and LCH color models are suitable because $L$ (Lightness) does not affect color [9].

A study has been made on the distinction between egg yolks from three manufacturers by their color components. Table 2 lists the results of distance functions based on data obtained with the video camera. Between manufacturer 1 and 3 , the distance values, regardless of the function used, are the largest. The distances between the color components for manufacturers 2 and 3 are significantly lesser. There are also lesser ones between manufacturers 1 and 2.

IRTIIE Vol. 7, No. 2, 2019 ISSN 1314-8788 (print), ISSN 1314-8796 (online), doi: 10.15547/artte.2019.02.005 
Table 1. Data of the color components used

\begin{tabular}{|c|c|c|c|c|c|c|c|}
\hline \multirow{2}{*}{\multicolumn{2}{|c|}{$\begin{array}{l}\text { Manufacturer } \\
\text { Color } \\
\text { component }\end{array}$}} & \multicolumn{2}{|c|}{$\begin{array}{c}\mathrm{P1}, \\
\text { mean } \pm S D\end{array}$} & \multicolumn{2}{|c|}{$\begin{array}{c}\mathbf{P 2}, \\
\text { mean } \pm \mathrm{SD}\end{array}$} & \multicolumn{2}{|c|}{$\begin{array}{c}\text { P3, } \\
\text { mean } \pm S D\end{array}$} \\
\hline & & VC & C & VC & $\mathrm{C}$ & VC & C \\
\hline \multirow{3}{*}{ RGB } & $\mathbf{R}$ & $234,37 \pm 15,47$ & $238,32 \pm 15,16$ & $233,65 \pm 16,62$ & $240,08 \pm 16,47$ & $238,90 \pm 12,03$ & $244,53 \pm 9,14$ \\
\hline & $\mathbf{G}$ & $140,29 \pm 37,13$ & $139,83 \pm 25,50$ & $145,34 \pm 14,51$ & $146,95 \pm 24,54$ & $146,03 \pm 13,08$ & $158,90 \pm 16,47$ \\
\hline & B & $98,22 \pm 32,45$ & $86,53 \pm 31,58$ & $60,33 \pm 16,73$ & $69,13 \pm 20,63$ & $18,65 \pm 22,61$ & $40,08 \pm 30,50$ \\
\hline \multirow{3}{*}{ Lab } & $L$ & $67,78 \pm 10,21$ & $66,35 \pm 5,75$ & $68,21 \pm 4,34$ & $67,71 \pm 5,17$ & $68,78 \pm 3,88$ & $70,16 \pm 3,97$ \\
\hline & $\mathbf{a}$ & $31,97 \pm 13,36$ & $28,47 \pm 9,56$ & $26,70 \pm 8,26$ & $24,91 \pm 8,18$ & $27,43 \pm 6,26$ & $20,88 \pm 5,25$ \\
\hline & b & $37,94 \pm 7,92$ & $36,75 \pm 9,17$ & $56,69 \pm 7,23$ & $46,23 \pm 5,82$ & $69,73 \pm 7,37$ & $55,25 \pm 7,31$ \\
\hline \multirow{3}{*}{ LCH } & L & $67,78 \pm 10,21$ & $66,35 \pm 5,75$ & $68,21 \pm 4,34$ & $67,71 \pm 5,17$ & $68,78 \pm 3,88$ & $70,16 \pm 3,97$ \\
\hline & C & $51,14 \pm 9,36$ & $47,65 \pm 8,04$ & $63,04 \pm 8,51$ & $52,98 \pm 7,15$ & $75,23 \pm 6,96$ & $59,42 \pm 6,19$ \\
\hline & H & $51,36 \pm 15,32$ & $52,18 \pm 0,12$ & $65,38 \pm 7,05$ & $62,21 \pm 0,07$ & $68,41 \pm 5,24$ & $68,94 \pm 0,06$ \\
\hline
\end{tabular}

Table 2. Distances obtained from video camera data

\begin{tabular}{|c|c|c|c|c|c|c|c|c|c|c|}
\hline \multirow{2}{*}{ Manufacturer } & Color model & \multicolumn{3}{|c|}{ RGB } & \multicolumn{3}{|c|}{ Lab } & \multicolumn{3}{|c|}{ LCH } \\
\hline & Distance function & $\mathbf{R}$ & $\mathbf{G}$ & B & $\mathbf{L}$ & $\mathbf{a}$ & b & $\mathbf{L}$ & $\mathbf{C}$ & $\mathrm{H}$ \\
\hline \multirow{6}{*}{ P1-P2 } & Mah & 1,74 & 1,76 & 1,75 & 1,77 & 1,66 & 1,65 & 1,77 & 1,69 & 1,63 \\
\hline & Eu & 27,81 & 47,34 & 44,01 & 13,36 & 18,01 & 12,39 & 13,36 & 14,82 & 18,20 \\
\hline & $\mathrm{Cb}$ & 34,79 & 57,23 & 54,72 & 16,16 & 22,80 & 15,16 & 16,16 & 18,79 & 22,38 \\
\hline & Mink & 27,81 & 47,34 & 44,01 & 13,36 & 18,01 & 12,39 & 13,36 & 14,82 & 18,20 \\
\hline & Cheb & 25,41 & 44,51 & 40,46 & 12,52 & 16,26 & 11,52 & 12,52 & 13,36 & 16,93 \\
\hline & FDR & 0,00 & 0,02 & 1,08 & 0,00 & 0,11 & 3,05 & 0,00 & 0,88 & 0,69 \\
\hline \multirow{6}{*}{ P1-P3 } & Mah & 1,76 & 1,76 & 1,74 & 1,76 & 1,73 & 1,65 & 1,76 & 1,76 & 1,71 \\
\hline & Eu & 24,23 & 46,38 & 48,79 & 13,00 & 17,35 & 12,59 & 13,00 & 14,51 & 17,72 \\
\hline & $\mathrm{Cb}$ & 30,35 & 55,47 & 58,85 & 15,67 & 21,02 & 15,29 & 15,67 & 17,88 & 20,79 \\
\hline & Mink & 24,23 & 46,38 & 48,79 & 13,00 & 17,35 & 12,59 & 13,00 & 14,51 & 17,72 \\
\hline & Cheb & 22,09 & 43,87 & 45,20 & 12,24 & 16,31 & 11,77 & 12,24 & 13,32 & 17,01 \\
\hline & FDR & 0,05 & 0,02 & 4,04 & 0,01 & 0,09 & 8,62 & 0,01 & 4,26 & 1,11 \\
\hline \multirow{6}{*}{ P2-P3 } & Mah & 1,75 & 1,77 & 1,71 & 1,77 & 1,69 & 1,69 & 1,77 & 1,67 & 1,71 \\
\hline & $\mathrm{Eu}$ & 25,03 & 24,39 & 33,45 & 7,28 & 12,26 & 12,33 & 7,28 & 12,79 & 10,46 \\
\hline & $\mathrm{Cb}$ & 31,33 & 31,02 & 40,60 & 9,20 & 15,51 & 15,27 & 9,20 & 15,67 & 13,29 \\
\hline & Mink & 25,03 & 24,39 & 33,45 & 7,28 & 12,26 & 12,33 & 7,28 & 12,79 & 10,46 \\
\hline & Cheb & 22,89 & 21,98 & 31,24 & 6,60 & 11,11 & 11,36 & 6,60 & 11,85 & 9,42 \\
\hline & $\begin{array}{l}\text { FDR } \\
\end{array}$ & 0,07 & 0,00 & 2,19 & 0,01 & 0,01 & 1,59 & 0,01 & 1,23 & 0,12 \\
\hline
\end{tabular}

Mah-Mahalanobis distance; Eu-Euclidean distance; Cb-cityblock distance; Mink-Minkouski Distance; Cheb-Chebichev distance; FDR-Fisher discriminant ratio

Table 3. Distances obtained by colorimeter data

\begin{tabular}{|c|c|c|c|c|c|c|c|c|c|c|}
\hline & & \multicolumn{3}{|c|}{ RGB } & \multicolumn{3}{|c|}{ Lab } & \multicolumn{3}{|c|}{ LCH } \\
\hline & & $\begin{array}{l}\mathbf{R} \\
\end{array}$ & $\mathbf{G}$ & B & L & $\mathbf{a}$ & b & $\mathbf{L}$ & C & $\mathrm{H}$ \\
\hline \multirow{6}{*}{ P1-P2 } & Mah & 1,74 & 1,76 & 1,75 & 1,77 & 1,66 & 1,65 & 1,77 & 1,69 & 1,63 \\
\hline & $\mathrm{Eu}$ & 27,81 & 47,34 & 44,01 & 13,36 & 18,01 & 12,39 & 13,36 & 14,82 & 18,20 \\
\hline & $\mathrm{Cb}$ & 34,79 & 57,23 & 54,72 & 16,16 & 22,80 & 15,16 & 16,16 & 18,79 & 22,38 \\
\hline & Mink & 27,81 & 47,34 & 44,01 & 13,36 & 18,01 & 12,39 & 13,36 & 14,82 & 18,20 \\
\hline & Cheb & 25,41 & 44,51 & 40,46 & 12,52 & 16,26 & 11,52 & 12,52 & 13,36 & 16,93 \\
\hline & FDR & 0,00 & 0,02 & 1,08 & 0,00 & 0,11 & 3,05 & 0,00 & 0,88 & 0,69 \\
\hline \multirow{6}{*}{ P1-P3 } & Mah & 1,76 & 1,76 & 1,74 & 1,76 & 1,73 & 1,65 & 1,76 & 1,76 & 1,71 \\
\hline & $\mathrm{Eu}$ & 24,23 & 46,38 & 48,79 & 13,00 & 17,35 & 12,59 & 13,00 & 14,51 & 17,72 \\
\hline & $\mathrm{Cb}$ & 30,35 & 55,47 & 58,85 & 15,67 & 21,02 & 15,29 & 15,67 & 17,88 & 20,79 \\
\hline & Mink & 24,23 & 46,38 & 48,79 & 13,00 & 17,35 & 12,59 & 13,00 & 14,51 & 17,72 \\
\hline & Cheb & 22,09 & 43,87 & 45,20 & 12,24 & 16,31 & 11,77 & 12,24 & 13,32 & 17,01 \\
\hline & FDR & 0,05 & 0,02 & 4,04 & 0,01 & 0,09 & 8,62 & 0,01 & 4,26 & 1,11 \\
\hline \multirow{6}{*}{ P2-P3 } & Mah & 1,75 & 1,77 & 1,71 & 1,77 & 1,69 & 1,69 & 1,77 & 1,67 & 1,71 \\
\hline & Eu & 25,03 & 24,39 & 33,45 & 7,28 & 12,26 & 12,33 & 7,28 & 12,79 & 10,46 \\
\hline & $\mathrm{Cb}$ & 31,33 & 31,02 & 40,60 & 9,20 & 15,51 & 15,27 & 9,20 & 15,67 & 13,29 \\
\hline & Mink & 25,03 & 24,39 & 33,45 & 7,28 & 12,26 & 12,33 & 7,28 & 12,79 & 10,46 \\
\hline & Cheb & 22,89 & 21,98 & 31,24 & 6,60 & 11,11 & 11,36 & 6,60 & 11,85 & 9,42 \\
\hline & FDR & 0,07 & 0,00 & 2,19 & 0,01 & 0,01 & 1,59 & 0,01 & 1,23 & 0,12 \\
\hline
\end{tabular}

Mah-Mahalanobis distance; Eu-Euclidean distance; Cb-cityblock distance; Mink-Minkouski Distance; Cheb-Chebichev distance; FDR-Fisher discriminant ratio 


\section{ARTTE $Y$}

Ipplied Resseirlores in Technics, Technologies and Educration

Journal of the Faculty of Technics and Technologies, Trakia University https://sites.google.com/a/trakia-uni.bg/artte/

Table 3 lists the results of distance functions based on data obtained with a colorimeter. The results match those obtained from video camera data. With the largest distance values, the $b$ (Lab) and $\mathrm{C}(\mathrm{LCH})$ color components are distinguished. These components will be used to assess the separation between the yolk color of different manufacturers.

Figure 5 shows classification results with a naive Bayesian color classification of egg yolks for manufacturers 2 and 3 . For these two manufacturers, as shown in the previous analyzes, data overlap is greatest. Significant overlap is observed with the selected C (LCH) color component, whereas for $b$ (Lab) it is less. An analysis needs to be made by assessing classification errors to determine the possibility of data separability from the three manufacturers on color components describing the yolks of the eggs produced by them.

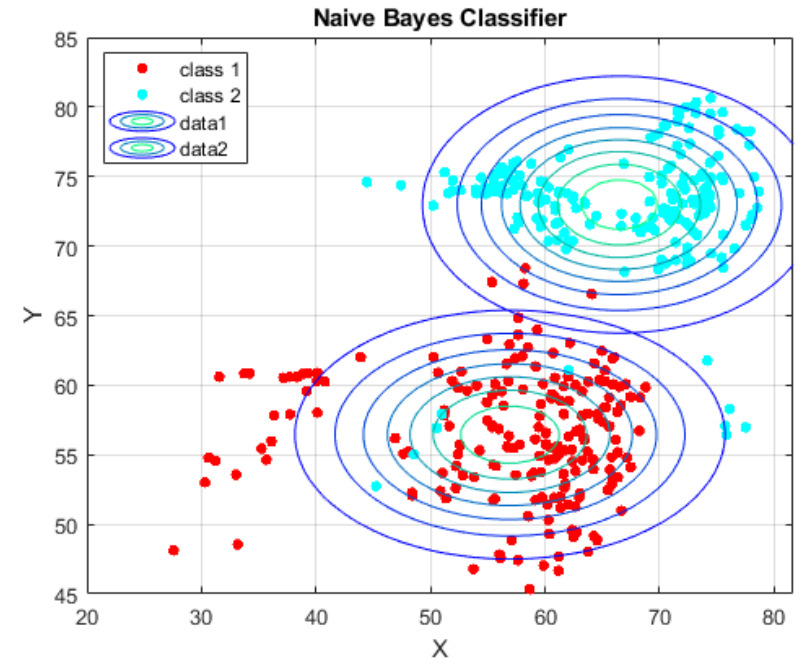

a) b (Lab)

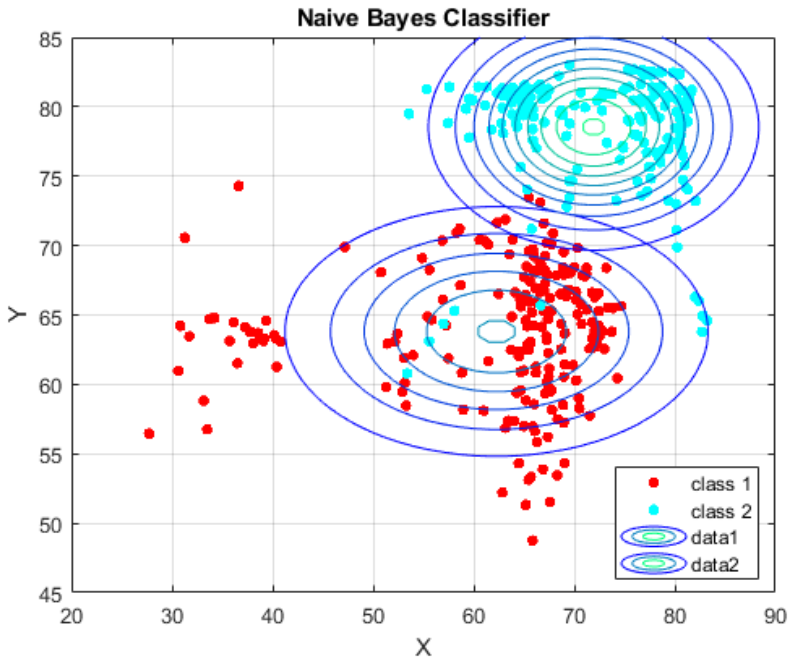

b) $\mathrm{C}(\mathrm{LCH})$

Figure 5. Results of a naive Bayesian classifier by color components

Tables 4, 5 and 6 show general classification errors with Naive Bayes classifier, Discriminant Analysis, and SVM by color components. The two selected color components $b$ (Lab) and C (LCH) were used to represent the data. The error resulting from the separability of egg yolks in 1 and 2 manufacturers is up to $16 \%$, while in the $3^{\text {rd }}$, the inaccuracy observed in the classification is more than $20 \%$. It can be seen that there is a strong differentiation between the two classes, mainly for the first and third manufacturers. Similar results were obtained using discriminant and SVM classifiers. The separability between yolks of different manufacturers in the selected color components has a general classification error of $5-16 \%$ with discriminant analysis and $2-14 \%$ using SVM.

Table 4. General classification error with naive Bayesian classifier by color components

\begin{tabular}{|c|c|c|c|}
\hline $\begin{array}{l}\text { Manufacturer } \\
\text { Color component }\end{array}$ & $\begin{array}{l}\text { P1-P2 } \\
\text { e, \% }\end{array}$ & $\begin{array}{l}\text { P1-P3 } \\
\text { e, \% }\end{array}$ & $\begin{array}{c}\text { P2-P3 } \\
\text { e, \% }\end{array}$ \\
\hline b (Lab) & $16 \%$ & $1 \%$ & $14 \%$ \\
\hline C (LCH) & $18 \%$ & $2 \%$ & $21 \%$ \\
\hline
\end{tabular}


Table 5. General classification error with a discriminant classifier by color components

\begin{tabular}{|l|r|r|r|r|r|r|}
\hline Color component & \multicolumn{3}{|c|}{ b (Lab) } & \multicolumn{3}{|c|}{$\mathbf{C}$ (LCH) } \\
\hline $\begin{array}{l}\text { Discriminant } \\
\text { function }\end{array}$ & $\begin{array}{c}\text { P1-P2 } \\
\text { e, \% }\end{array}$ & $\begin{array}{c}\text { P1-P3 } \\
\text { e, \% }\end{array}$ & $\begin{array}{c}\text { P2-P3 } \\
\text { e, \% }\end{array}$ & $\begin{array}{c}\text { P1-P2 } \\
\text { e, \% }\end{array}$ & $\begin{array}{c}\text { P1-P3 } \\
\text { e, \% }\end{array}$ & $\begin{array}{c}\text { P2-P3 } \\
\text { e, \% }\end{array}$ \\
\hline $\mathbf{Q}$ & $16 \%$ & $5 \%$ & $14 \%$ & $16 \%$ & $8 \%$ & $14 \%$ \\
\hline DQ & $15 \%$ & $5 \%$ & $14 \%$ & $16 \%$ & $8 \%$ & $14 \%$ \\
\hline M & $16 \%$ & $5 \%$ & $14 \%$ & $16 \%$ & $8 \%$ & $14 \%$ \\
\hline Q-quadratic; DQ-diagonal-quadratic; M-Mahalanobis; P1, P2, P3-manufacturers
\end{tabular}

Table 6. General classification error with SVM classifier by color components

\begin{tabular}{|l|r|r|r|r|r|r|}
\hline Color component & \multicolumn{3}{|c|}{ b (Lab) } & \multicolumn{3}{|c|}{ C (LCH) } \\
\hline Function & $\begin{array}{c}\text { P1-P2 } \\
\text { e, \% }\end{array}$ & $\begin{array}{c}\text { P1-P3 } \\
\text { e, \% }\end{array}$ & $\begin{array}{c}\text { P2-P3 } \\
\text { e, \% }\end{array}$ & $\begin{array}{c}\text { P1-P2 } \\
\text { e, \% }\end{array}$ & $\begin{array}{c}\text { P1-P3 } \\
\text { e, \% }\end{array}$ & $\begin{array}{c}\text { P2-P3 } \\
\text { e, \% }\end{array}$ \\
\hline Q & $13 \%$ & $2 \%$ & $11 \%$ & $14 \%$ & $6 \%$ & $12 \%$ \\
\hline Poly & $12 \%$ & $2 \%$ & $11 \%$ & $14 \%$ & $6 \%$ & $12 \%$ \\
\hline RBF & $13 \%$ & $2 \%$ & $11 \%$ & $14 \%$ & $6 \%$ & $12 \%$ \\
\hline P1, P2, P3-manufacturers; Q-quadratic; Poly-polynomial; RBF-radial basis function \\
\hline
\end{tabular}

Verification has been made of the separability between egg yolks from three manufacturers on their spectral characteristics. Figure 6 shows spectral characteristics of yolks from three manufacturers. The spectral characteristics of reflection, transmission and absorption for individual manufacturers overlap. For this reason, the averaged spectra are displayed.

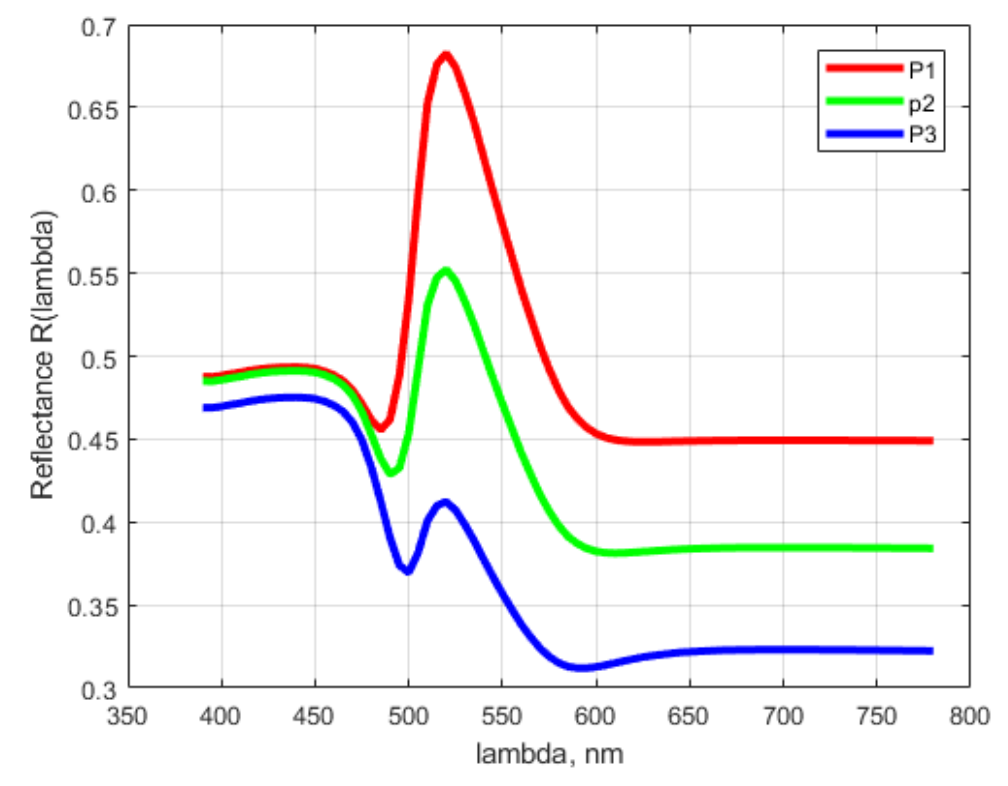

Figure 6a.

Spectral characteristics of egg yolks from different manufacturers.

Reflection 


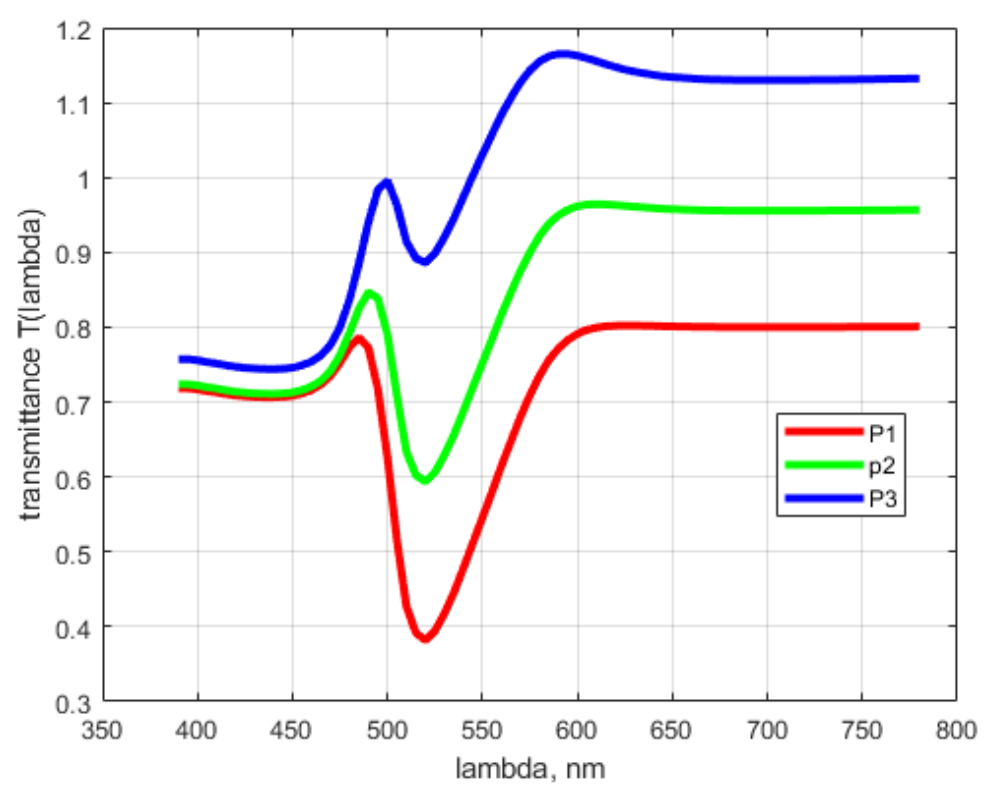

Figure 6b.

Spectral characteristics of egg yolks from different manufacturers.

Transmission

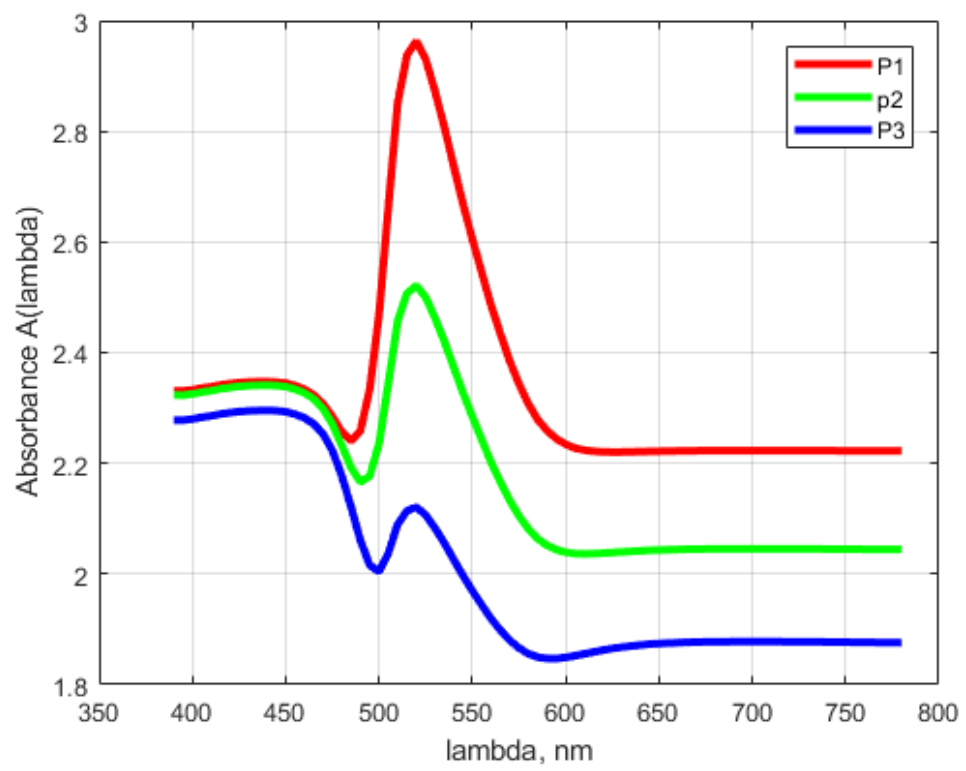

Figure 6c.

Spectral characteristics of egg yolks from different manufacturers. Absorption 


\section{AR'TIE

Functions are provided to reduce the spectral characteristics data. Figure 7 shows results of methods for reducing the spectral characteristics data. When using area under curve (AUC), linear principal components and latent variables, there was a greater overlap of the experimental data compared to those obtained with the kernel variant of principal components. The main reason for this is that in the first three methods, the obtained reduced data are close to the real spectral characteristics [25].

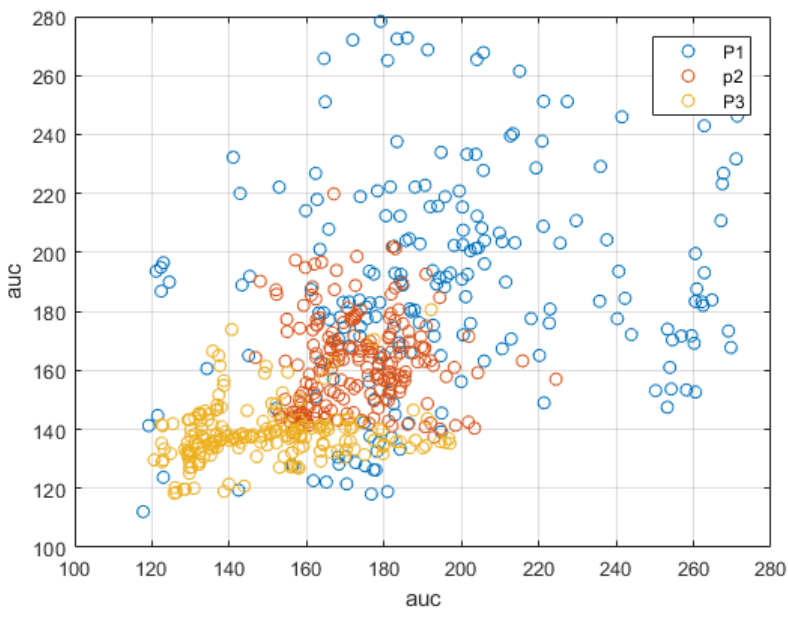

a) AUC

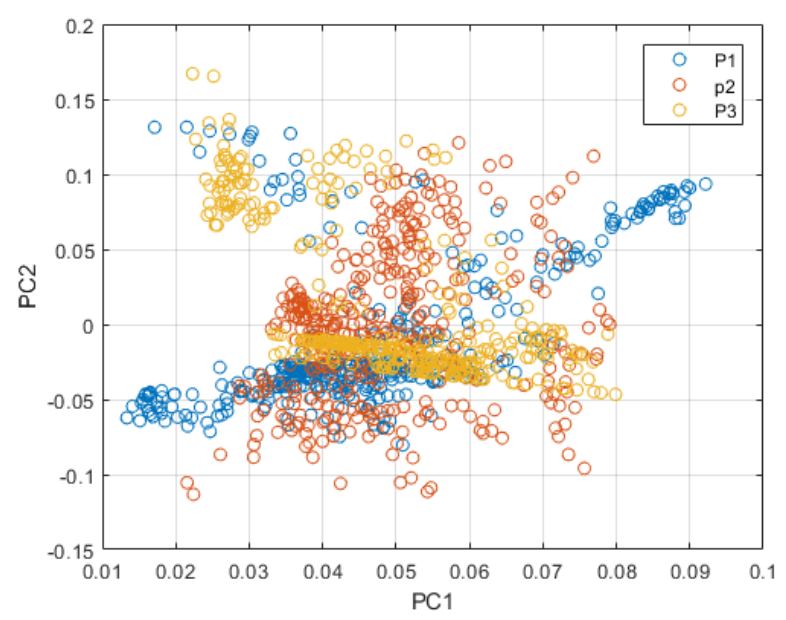

c) PC

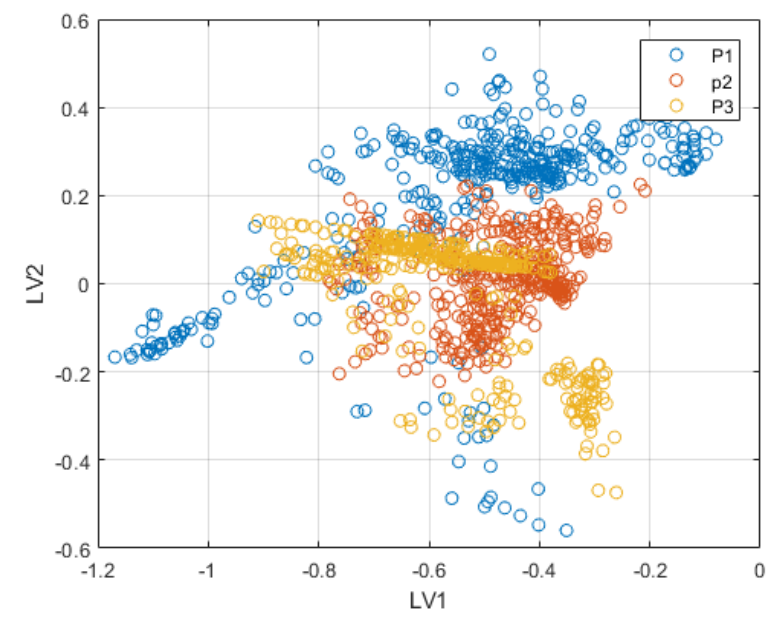

b) LV

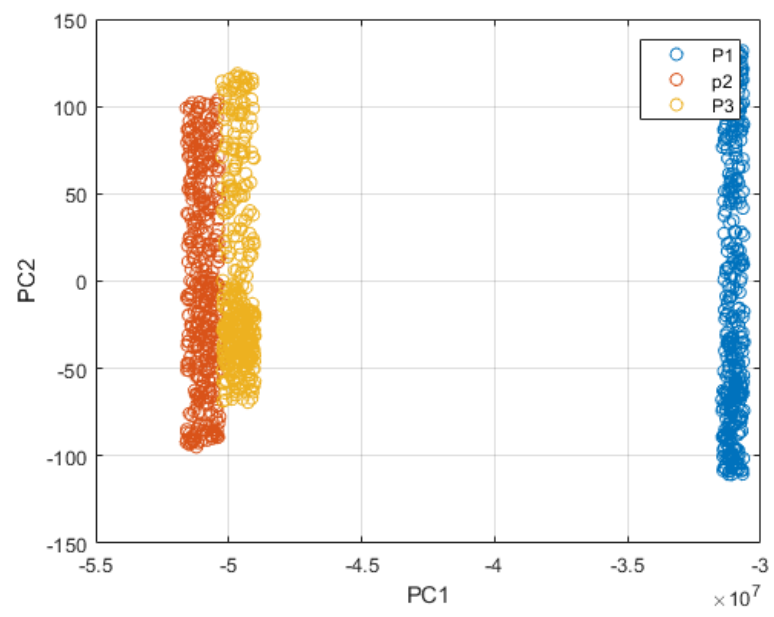

d) $\mathrm{kPC}$

Figure 7. Spectral Data Reduction.

AUC-area under curve; LV-latent variables; PC-principal components; kPC-kernel PCA

As can be seen from the results presented, a large overlap is observed between the data for manufacturers 2 and 3 . For this reason, a preview of the Bayes classifier's work with this data is presented here. Figure 8 shows the results of a naive Bayes classifier. The figure shows that the separation between the two manufacturers was observed using a kernel variant of principal components. In all other cases, the most overlapping of the experimental data is obtained. 


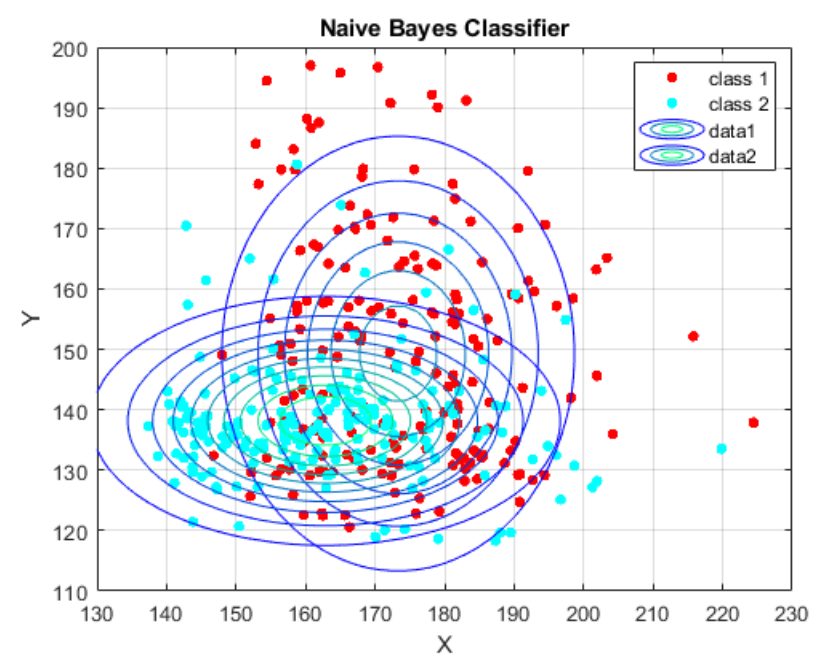

a) AUC

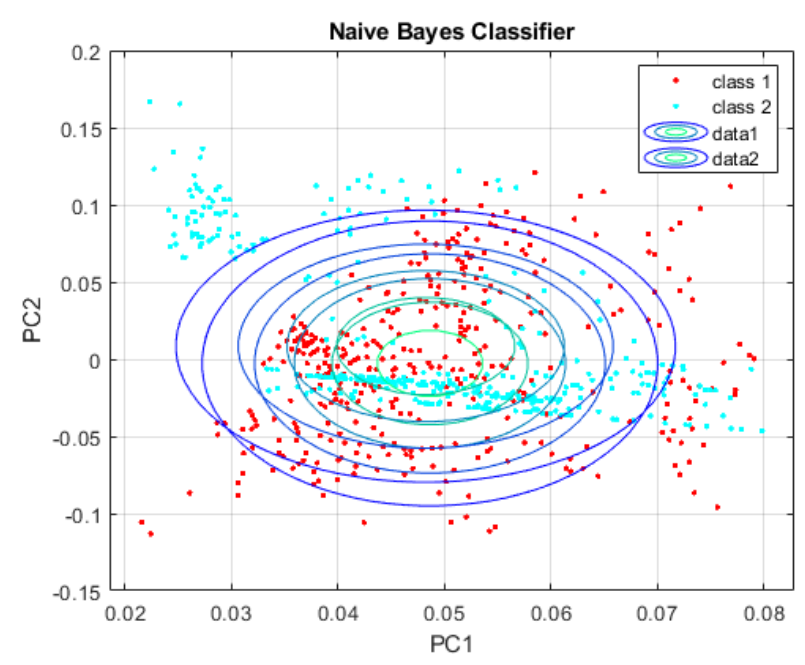

c) $\mathrm{PC}$

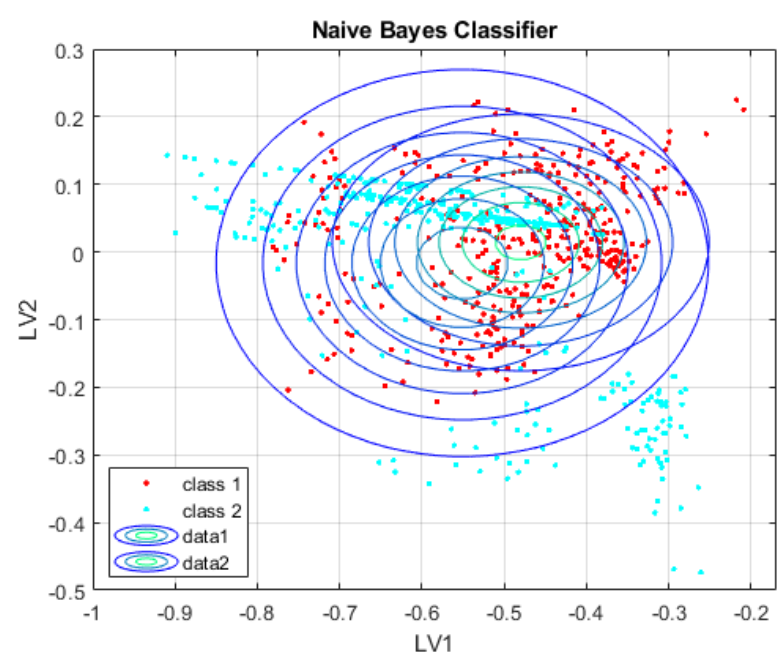

b) LV

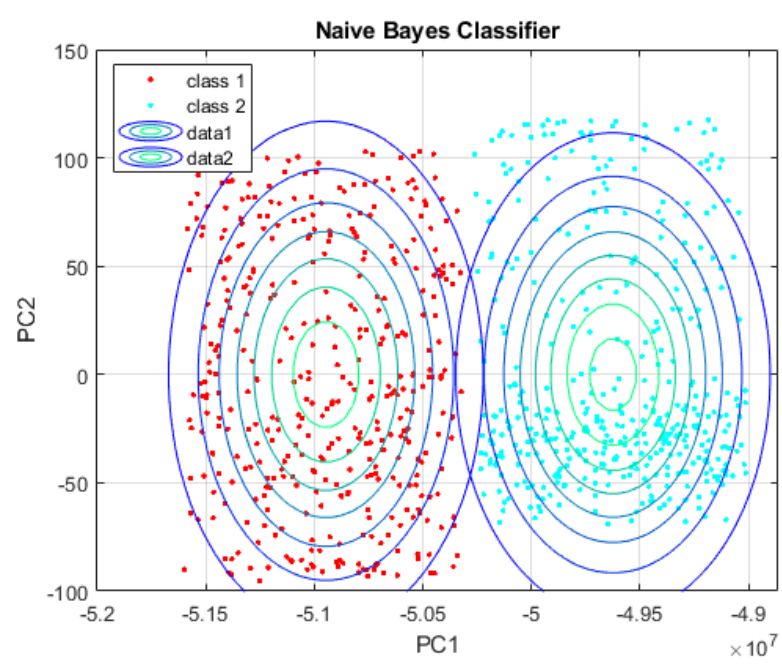

d) $\mathrm{kPC}$

Figure 8.

Results of a naive Bayesian classifier on reduced spectral data.

AUC-area under curve; LV-latent variables;

PC-principal components; kPC-kernel PCA

Tables 7, 8 and 9 represent the results of classification with naive Bayes classifier, discriminant analysis and SVM. The use of a Bayesian classifier shows low values of the general classification error with the kernel PCA data representation method between the three manufacturers. Good results are obtained by separability performed with nonlinear discriminant analysis and SVM kernel variant combined with the kernel variant of the principal components. With the other three data visualization models, the base classifier shows an inaccuracy of class attrition significantly exceeding $20 \%$. 
Table 7. General error on naive Bayesian classifier by reduced spectral data

\begin{tabular}{|c|c|c|c|c|}
\hline $\begin{array}{l}\text { Data reduction method } \\
\text { Manufacturers }\end{array}$ & $\begin{array}{l}\text { AUC } \\
\text { e, \% }\end{array}$ & $\begin{array}{c}\text { LV } \\
\text { e, \% }\end{array}$ & $\begin{array}{c}\mathbf{P C} \\
\mathbf{e}, \%\end{array}$ & $\begin{array}{l}\text { kPC } \\
\text { e, \% }\end{array}$ \\
\hline $\begin{array}{ll}\text { P1-P2 } \\
\end{array}$ & $37 \%$ & $8 \%$ & $41 \%$ & $0 \%$ \\
\hline P1-P3 & $34 \%$ & $10 \%$ & $30 \%$ & $0 \%$ \\
\hline P2-P3 & $32 \%$ & $35 \%$ & $55 \%$ & $1 \%$ \\
\hline
\end{tabular}

Table 8. General Classification error on Discriminant Classifier by reduced spectral data

\begin{tabular}{|l|r|r|r|r|r|r|}
\hline \multicolumn{1}{|c|}{ Mata reduction method } & \multicolumn{2}{|c|}{ LV } & \multicolumn{3}{|c|}{ kPC } \\
\hline \multirow{2}{*}{ Discriminant function } & \multirow{2}{*}{ P1-P2 } & P1-P3 & P2-P3 & P1-P2 & P1-P3 & \multicolumn{1}{|c|}{ P2-P3 } \\
\hline Q & & & & & & $2 \%$ \\
\hline DQ & $25 \%$ & $25 \%$ & $33 \%$ & $2 \%$ & $2 \%$ & $0 \%$ \\
\hline M & $25 \%$ & $23 \%$ & $32 \%$ & $0 \%$ & $0 \%$ & $0 \%$ \\
\hline P & $48 \%$ & $23 \%$ & $47 \%$ & $0 \%$ & $0 \%$ & $0 \%$ \\
\hline
\end{tabular}

P1, P2, P3-manufacturers; LV-latent variables; kPC-kernel variant of principal compoents; Q-

quadratic; DQ-diagonal-quadratic; M-mahalanobis

Table 9. General Classification error on SVM Classifier by reduced spectral data

\begin{tabular}{|l|r|r|r|r|r|r|}
\hline Data reduction method & \multicolumn{3}{|c|}{ LV } & \multicolumn{2}{|c|}{ kPC } \\
\hline Function & \multirow{2}{*}{ P1-P2 } & P1-P3 & P2-P3 & P1-P2 & P1-P3 & P2-P3 \\
\hline Q & & & & & & $1 \%$ \\
\hline Poly & $15 \%$ & $6 \%$ & $25 \%$ & $1 \%$ & $1 \%$ & $1 \%$ \\
\hline RBF & $0 \%$ & $1 \%$ & $3 \%$ & $0 \%$ & $0 \%$ & $0 \%$ \\
\hline
\end{tabular}

P1, P2, P3-manufacturers; LV-latent variables; kPC-kernel variant of principal compoents; Qquadratic; Poly-polynomial; RBF-radial basis function

\section{CONCLUSION}

Image-processing and image analysis techniques have revealed for visible properties of three types of egg yolks and a comparative analysis of these properties has been made. A similarity of the color characteristics of products from different manufacturers has been established.

Using a naive Bayes classifier with the two selected color components to represent the data, a general error of classification with lower values was obtained with $b$ (Lab) and $C(\mathrm{LCH})$ color components in separability of egg yolks from different manufacturers. It is from $1 \%$ to $21 \%$ with these two color components.

Using discriminant and kernel variants of SVM classifiers for data analysis, they show good data separation with a general error of up to $12 \%$ using non-linear separating functions. It is inefficient to use a quadratic separating function in data separation by the three manufacturers, with an inaccuracy of up to $14 \%$ regardless of the color component used to represent the data.

In the studies of the spectral characteristics of egg yolks from different manufacturers, the highest accuracy of separation of the target areas is obtained with the kernel SVM classifier combined with the kernel variant of the principal components. When using this classifier, general classification errors of up to $1 \%$ were obtained. When using a kernel variant of

IRTIIE Vol. 7, No. 2, 2019 ISSN 1314-8788 (print), ISSN 1314-8796 (online), doi: 10.15547/artte.2019.02.005 
principal components, the two groups of points corresponding to the spectral characteristics of egg yolks from different manufacturers are sufficiently compact and spaced apart, which explains the results obtained for separating these areas using the classifiers used.

The results of the data separability study within a particular class indicate that better results are obtained in the studies based on spectral data in the visible range. The results confirm the hitherto known research in this area because the major part of the chicken egg yolks properties studied are visible properties that can be analyzed in the visible spectrum of the reflected light.

\section{ACKNOWLEDGEMENTS}

The research in this article is supported by grant 6.OUP/ 25.04.2017 "Construction of laboratory for photogrammetric and remote measuring methods".

\section{REFERENCES}

[1] Alay T., F. Karadas. (2017). The effects of carotenoids in quail breeder diets on egg yolk pigmentation and breeder performance. Department of Animal Science, Agriculture Faculty, Yuzuncu Yil University, Van, Turkey, 2017.

[2] Arabadzieva-Kalcheva N., N. Nikolov. (2017). Comparative analysis of the naive bayes classifier and sequential minimal optimization for classifying text in bulgarian in machine learning. Computer science and technologies. Year XV, No.1, ISSN 1312-3335, pp.97105 (in Bulgarian).

[3] Barbosa V., A. Gaspar, L. Calixto, T. Simões, P. Agostinho. (2011). Stability of the pigmentation of egg yolks enriched with omega-3 and carophyll stored at room temperature and under refrigeration. Revista Brasileira de Zootecnia, Vol. 40, No. 7, pp. 1540-1544.

[4] Baycheva S. (2016). Application of devices of measurement of color in analysis of food products. Innovation and entrepreneurship - Applied scientific journal, Vol. 4, No. 4, 2016, ISSN 1314-9253, pp. 43-59.

[5] Baylan M., L. Celik, G. Akpinar, S. Alasahan, A. Kucukgul, S. Dogan. (2017). Influence of eggshell colour on egg yolk antibody level, incubation results, and growth in broiler breeders. Revista Brasileira de Zootecnia, Vol. 46, No. 2, pp. 105-112.

[6] Beardsworth P. M., J-M. Hernandez. (2004). Yolk colour - an important egg quality attribute. International Poultry Production, Vol. 12, No. 5, pp. 17-18.

[7] BenSaïda A. Shapiro-Wilk and Shapiro-Francia normality tests. https://www.mathworks.com/matlabcentral/fileexchange/13964-shapiro-wilk-and-shapirofrancia-normality-tests. (available on 17.09.2018).

[8] Bovšková H., K. Míková, Z. Panovská. (2014). Evaluation of Egg Yolk Colour. Czech Journal of Food Science, Vol. 32, No. 3, 2014, pp. 213-217.

[9] CIE 2006 "Physiologically-relevant" LMS functions. http://www.cvrl.org/. (available on 21.06.2019).

[10] Cuevas C., R. Estrada, A. Menocal, A. González, L. Coello. (2015). Effect of Feeding Low-Oil Ddgs to Laying Hens and Broiler Chickens on Performance and Egg Yolk and Skin Pigmentation. Brazilian Journal of Poultry Science, Vol. 17, No.2, pp. 247-254.

[11] Damyanov Ch., V. Nachev, T. Titova. (2010). Bayes classifiers. Journal Automatics and informatics, Vol. 2, pp. 54-61.

[12] Englmaierová M., M. Skřivan, I. Bubancová. (2013). A comparison of lutein, spray-dried Chlorella, and synthetic carotenoids effects on yolk colour, oxidative stability, and 
reproductive performance of laying hens. Czech Journal of Animal Science, Vol. 58, No. 9, pp. 412-419.

[13] Faitarone P., E. Garcia, R. Roça, E. Andrade, F. Vercese, K. Pelícia. (2016). Yolk Color and Lipid Oxidation of the Eggs of Commercial White Layers Fed Diets Supplemented with Vegetable Oils. Brazilian Journal of Poultry Science, Vol. 18, No. 1, pp. 9-16.

[14] Glassner A. (1989). How to derive a spectrum from an RGB triplet. IEEE Computer Graphics and Applications 9, 4 (July 1989), pp. 95-99.

[15] Hasin B., A. Ferdaus, M. Islam, M. Uddin, M. Islam. (2006). Marigold and Orange Skin as Egg Yolk Color Promoting Agents. International Journal of Poultry Science, Vol. 5, No. 10 , pp. 979-987.

[16] Karadas F., E. Grammenidis, P. Surai, T. Acamovic, N. Sparks. (2006). Effects of carotenoids from lucerne, marigold and tomato on egg yolk pigmentation and carotenoid composition. Brazilian Poultry Science, Vol. 47, No. 5, pp. 561-6.

[17] Kazlacheva Z., J.llieva, M. Zhekova, P. Dineva. (2014), Fashion design on the base of connection between colors and lines. ARTTE Applied Researches in Technics, Technologies and Education, Vol. 2, No. 1, 2014, ISSN 1314-8796, pp. 54-64.

[18] Kirilova, E., P. Daskalov, R. Tsonev, Ts. Draganova. (2010). Selection of colour features for recognition of Fusarium damaged corn seeds. Annual Conference RU \& SU, Vol. 49, Book 3.1, ISSN 1311-3321, pp. 125-130, (in Bulgarian).

[19] Kotrbáček V., M. Skřivan, J. Kopecký, O. Pěnkava, P. Hudečková, I. Uhríková, J. Doubek. (2013). Retention of carotenoids in egg yolks of laying hens supplemented with heterotrophic Chlorella. Czech Journal of Animal Science, Vol. 58, No. 5, pp. 193-200.

[20] Laca A., B. Paredes, M. Díaz. (2010). Possibilities of yolk rheological measurements to characterise egg origin and processing properties. Afinidad LXVI, Vol. 546, pp. 119-122.

[21] Lukanov H. (2014). Egg quality traits in layers from different production types. Agricultural Science And Technology, Vol. 6, No. 2, pp.148-151.

[22] Lukanov H. (2019). Meat colour characteristics of different productive types domestic quails. Trakia Journal of Sciences, No. 1, pp. 42-48.

[23] Mather J. (2010). Spectral and XYZ Color Functions. www.mathworks.com. (available on 14.06.2018).

[24] Min B., K. Nam, E. Lee, G. Ko, D. Trampel, D. Ahn. (2005). Effect of Irradiating Shell Eggs on Quality Attributes and Functional Properties of Yolk and White. Poultry Science, Vol. 84, No. 11, pp. 1791-1796.

[25] Mladenov M. (2015). Complex assessment of the quality of food products through visual images, spectrophotometric and image analysis hyper-spectral characteristics. Monograph. University publishing Center of Rousse University "A. Kanchev", Rousse, 2015 (in Bulgarian).

[26] Mladenov, M., S. Penchev, M. Deyanov. (2015). Complex assessment of food products quality using analysis of visual images, spectrophotometric and hyperspectral characteristics. International Journal of Engineering and Innovative Technology (IJEIT), Vol. 4, Issue 12, June 2015, ISSN: 2277-3754, pp. 23-32.

[27] Narinc D., A. Aygun, H. Kucukonder, T. Askoy, E. Gurcan. (2015). An Application of Bootstrap Technique in Animal Science: Egg Yolk Color Sample. Kafkas Üniversitesi Veteriner Fakültesi Dergisi, Vol. 21, No. 5, pp. 631-637.

[28] Roberson K., J. Kalbfleisch, W. Pan, R. Charbeneau. (2005). Effect of Corn Distiller's Dried Grains with Solubles at Various Levels on Performance of Laying Hens and Egg Yolk Color. International Journal of Poultry Science, Vol. 4, No. 2, pp. 44-51.

[29] Rossi P., J. Nunes, F. Rutz, M. Anciuti, P. Moraes, S. Takahashi, A. Bottega, J. Dorneles. (2015). Effect of sweet green pepper on yolk color and performance of laying hens. The Journal of Applied Poultry Research, Vol. 24, Issue 1, March, 2015, pp.1014.

IRTITE Vol. 7, No. 2, 2019 ISSN 1314-8788 (print), ISSN 1314-8796 (online), doi: 10.15547/artte.2019.02.005 


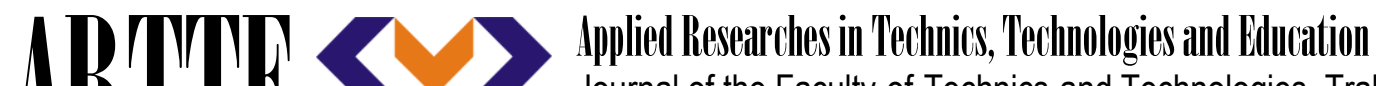 Journal of the Faculty of Technics and Technologies, Trakia University https://sites.google.com/a/trakia-uni.bg/artte/}

[30] Sheridan M. (2018). Method and apparatus to determine colour of egg yolk. Burlington (CA), 2018.

[31] Titova T., V. Nachev, Ch. Damyanov. (2012). Non-destructive egg quality determination with intelligent classifiers. XI International SAUM Conference on Systems, Automatic Control and Measurements, Niš, Serbia, November $14^{\text {th }}-16^{\text {th }}, 2012$, pp. 451-454.

[32] Titova T., V. Nachev, Ch. Damyanov, N. Bozukov, H. Dinkov. (2012). Determining the freshness of eggs using spectral data and wavelet network model. Zbornik radova 56. Konferencije za ETRAN, Zlatibor, Serbia, 11-14 June 2012, pp. VI1.5-1.4.

[33] Titova T., V. Nachev, Ch. Damyanov, P. Nikovski. (2013). Intelligent classifiers for nondestructive determination of food quality. Facta Universitatis, Series: Automatic Control and Robotics, Vol. 12, No. 1, pp. 19-30.

[34] Yankov K. (2015). Assessment of processes using identification models. Applied research on technics, technologies and education ARTTE Applied Researches in Technics, Technologies and Education, Vol. 3, No. 1, ISSN 1314-8796, pp. 52-60. 